NBER WORKING PAPER SERIES

\title{
WELFARE REFORM AND NON-MARITAL \\ FERTILITY IN THE 1990s: \\ EVIDENCE FROM BIRTH RECORDS
}

\author{
Theodore Joyce \\ Robert Kaestner \\ Sanders Korenman \\ Working Paper 9406 \\ http://www.nber.org/papers/w9406

\section{NATIONAL BUREAU OF ECONOMIC RESEARCH 1050 Massachusetts Avenue Cambridge, MA 02138} \\ December 2002
}

Research supported by a grant from the National Institutes of Health (NICHD). The views expressed herein are those of the authors and not necessarily those of the National Bureau of Economic Research.

(C) 2002 by Theodore Joyce, Robert Kaestner, and Sanders Korenman. All rights reserved. Short sections of text not to exceed two paragraphs, may be quoted without explicit permission provided that full credit including, (C) notice, is given to the source. 
Welfare Reform and Non-Marital Fertility in the 1990s:

Evidence from Birth Records

Theodore Joyce, Robert Kaestner, and Sanders Korenmen

NBER Working Paper No. 9406

December 2002

JEL No. I3, J1

\section{ABSTRACT}

The 1996 Personal Responsibility Work Opportunity Reconciliation Act dramatically altered the economic incentive to bear children out-of-wedlock for economically disadvantaged women or couples most likely to avail themselves of welfare programs. We use data from vital statistics and a difference-indifferences research design to investigate whether state and federal welfare reform in the 1990s reduced rates of non-marital childbearing among women aged 19 to 39 at highest risk of welfare use, relative to women at lower risk. We find little consistent evidence for an effect of welfare reform on non-marital childbearing. This finding is similar to the literature that found little or mixed evidence for an effect of AFDC benefits. If anything, federal welfare reform has been associated with a small positive effect of two to three percent for white and black women ages 19 to 39 .

Theodore Joyce

NBER 365 Fifth Avenue, 5th Floor

New York, NY 10016-4309

Ted_Joyce@baruch.cuny.edu

\author{
Robert Kaestner \\ Institute of Government \\ and Public Affairs \\ University of Illinois at Chicago \\ 815 West Van Buren Street, Suite 525 \\ Chicago, IL 60607 \\ and NBER \\ Kaestner@uic.edu
}

Sanders Korenman

School of Public Affairs

Baruch College

17 Lexington Avenue, Box C-408

New York, NY 10010

sanders_korenman@baruch.cuny.edu 
"Therefore, in light of this demonstration of the crisis in our nation, it is the sense of the Congress that prevention of out-of-wedlock pregnancy and reduction in out-of-wedlock birth are very important Government interests and the policy contained in part A of Title IV of the Social Security Act ... is intended to address the crisis." (Findings - H.R. 3734 - The Personal Responsibility and Work Opportunity Reconciliation Act of 1996)

Was Congress successful? Did welfare reform achieve one of Congress' major goals - the prevention of out-of-wedlock pregnancy and a reduction in non-marital fertility? Surprisingly, the answer to this question is unknown, as evidence remains scarce even five years after the law went into effect. Indeed, in a recent position paper on welfare reform reauthorization, Working Toward Independence, ${ }^{1}$ the Bush Administration remarks on the lack of evidence on this question and requests $\$ 100$ million for research and demonstration projects on family formation and healthy marriages. The Administration also requests $\$ 100$ million in matching grants to support innovative state and local programs intended to reduce out-of-wedlock births. From the Bush Administration's perspective, therefore, welfare reform has not prompted states to make sufficient effort to curb nonmarital childbearing, and without such effort the goal of reducing nonmarital birth is less likely to be achieved.

Data published by the Centers for Disease Control and Prevention bolster the view that welfare reform has not reduced nonmarital fertility. Although births per 1000 unmarried women age 15 to 44 fell from 45.6 in 1994-96, just prior to reform, to 44.1 1997-99, just after reform.(Ventura and Bachrach 2000), the post-reform non-marital birth rate is approximately the same as it was in the early 1990s, and remains high by historical standards. Moreover, the entire decline in nonmarital fertility post-welfare reform is due to a decline among black women, which began in 1990, well before welfare reform (with no acceleration of this decline after welfare reform). In sum, these national data would appear to suggest that welfare reform had little effect on nonmarital childbearing. Although the trends in aggregate rates of nonmarital fertility are quite suggestive, a firmer conclusion requires a more refined evaluation. In particular, the aggregate data do not allow an investigation of the variation in the timing and intensity of welfare

\footnotetext{
${ }^{1}$ (www.whitehouse.gov/news/releases/2002/02/welfare-reform-announcement-book.html)
} 
reform in different states, nor do they focus on the populations most likely to be affected by welfare policy.

Out-of-wedlock birth has been and continues to be a politically contentious issue. It is unfortunate, therefore, that the ongoing debate over reauthorization of the federal welfare reform act (PRWORA, the Personal Responsibility and Work Opportunity Reconciliation Act), which involves

debate over reducing non-marital births, has not been informed by much recent social science research on this subject. Additional research is needed, and the purpose of this paper is to explore whether recent state and federal welfare reform reduced non-marital fertility in populations at highest risk of welfare use.

\section{Previous Research}

Although there is not much research on the effect of the PRWORA and earlier state reforms on non-marital birth, a considerable literature has investigated the effects of the AFDC (Aid to Families with Dependent Children) program on fertility. Moffitt (1998) provides a comprehensive review of this literature, and specifically reviews evidence on the effects of AFDC on fertility, including out-of-wedlock birth. Based on 68 estimates from numerous studies, he concludes that government cash assistance affects out-of-wedlock birth, but that the magnitude of the effect is uncertain. Moffitt also emphasizes that this conclusion is subject to significant qualification because a number of studies find no effect. For example, estimates from studies that control for state fixed-effects, which are generally preferred by analysts to estimates based on cross-state variation in welfare policy alone, reveal a decidedly mixed pattern of results: six find insignificant effects, 11 find significant effects (i.e., higher AFDC benefits increase fertility), and two report mixed results. Although Moffitt (1998) concludes that researchers generally agree that welfare policy influences fertility, he regards the evidence to be too weak to support definitive policy recommendations. Moreover, studies of the AFDC program may not provide evidence relevant to PRWORA because of the relatively small variation in welfare policy that the studies of the AFDC program examined. Recent welfare reform represents a striking change from past policy, and thus 
provides a sharper test of the effects of public assistance, and economic incentives more generally, on non-marital fertility.

As noted, there have been few studies of the effect of recent welfare reform on fertility. In an experimental evaluation, Camasso et al. (1998) investigated the effect of the "family cap" provision in New Jersey. This study finds that the family cap reduced the birth rate by nine percent among women receiving public assistance. Horvath and Peters (2000) also studied the effect of the family cap (as well as other AFDC waiver provisions) on the nonmarital birth ratio, and report a similar finding. ${ }^{2}$

Surprisingly, other waiver provisions, such as time-limited benefits and work requirements (which are prominent in PRWORA), did not have a consistent effect on the nonmarital birth ratio, even though these policies embody stronger financial incentives than family cap provisions. In contrast, Kearney (2001) and Levine (2002) find no effects of family caps on nonmarital fertility. However, both of these studies report that higher AFDC benefits are associated with significant increases in nonmarital fertility, consistent with the conclusion reached by Moffitt (1998). Notably, however, neither study examines the effect of the dramatic changes in policy that occurred as a result of PRWORA.

Two other studies are relevant to our analysis. Schoeni and Blank (2000) examine the effect of AFDC waivers and TANF on female headship and find that recent welfare reforms reduced female headship among less-educated women by two percentage points, or approximately eight percent. Kaushal and Kaestner (2001) investigate whether time limits and family cap provisions affected birth rates among unmarried women. They find that time limits reduced by 18 to 47 percent the probability that a lesseducated woman will have a non-marital birth, but the estimates are not always statistically significant.

To summarize, the literature provides some evidence that fertility is sensitive to changes in AFDC generosity, but evidence from the larger literature on whether the fertility of poor women responds to financial incentives is inconclusive. Further, recent welfare reform has produced unprecedented and

\footnotetext{
${ }^{2}$ Kearney (2001) criticizes Horvath and Peters (2000) for using this dependent variable because it confounds marriage and fertility responses. Kearney (2000) also notes that the estimates reported in Horvath and Peters (2000) are quite large, perhaps implausibly so, particularly since the sample is not limited to women most at risk of welfare receipt.
} 
dramatic shifts in the incentives for non-marital childbearing. The most credible estimates of the effect on fertility of the AFDC program, by contrast, examined the relatively small changes over time in benefit levels within states. Thus, little is known about the effect of current welfare reform efforts on non-marital fertility, and this circumstance underscores the value of the analysis we present below.

\section{Research Design and Statistical Methods}

The hypothesis underlying our empirical analysis is the following. Recent state and federal welfare reform, which, among other provisions, limits cash assistance to five years and requires work in return for cash assistance, has increased the (expected) cost of raising children, especially for single parents. In response, women or couples, particularly those who were most likely to avail themselves of public assistance after a birth, will reduce non-marital fertility. This hypothesis is consistent with a number of behavioral models of fertility that share the common assumption that women respond to economic incentives (e.g., money cost of fertility control) when making fertility decisions. ${ }^{3}$

To examine this hypothesis, we use a "pre- and post-test with comparison group" research design, which is often referred to as a difference-in-differences (DD) approach. ${ }^{4}$ The pre- and post-test periods correspond to pre- and post-welfare reform. We define target and comparison groups on the basis of mother's education and marital status. We define two target groups: unmarried women with less than 12 years of education and unmarried women with 12 years of education. Similarly, we define two comparison groups: married women with less than 12 years of education and unmarried women with between 13 and 15 years of education. Education and marital status are important predictors of welfare use (see Table 1). Unmarried, less-educated women have high rates of welfare receipt and are likely to be affected by welfare reform; married, less-educated women and unmarried women with more than a high school degree have low rates of welfare receipt and are unlikely to be affected. We provide further

\footnotetext{
${ }^{3}$ See for example, Becker (1981), Becker and Lewis (1973), Michael and Willis (1975), the review by Montgomery and Trussell (1986), and Grogger et al. (2002).

${ }^{4}$ Technically, we are estimating a difference-in-difference-in-differences (DDD) model since we are using crossstate variation in addition to the pre- and post-period.
} 
evidence below on the adequacy of these definitions. A strength of the pre- and post-test with comparison group research design is the focus on the populations most affected by policy changes. ${ }^{5}$

To implement this research design, we estimate the following regression model:

$\ln \mathrm{N}_{-} \mathrm{OWB}_{\mathrm{ijt}}=\alpha_{1}$ policy $_{\mathrm{jt}}+\sum_{\mathrm{j}} \delta_{\mathrm{j}}$ state $_{\mathrm{j}}+\sum_{\mathrm{j}} \sum_{\mathrm{t}} \lambda_{\mathrm{jt}}\left(\right.$ state $_{\mathrm{j}} \mathrm{x}$ time $\left._{\mathrm{t}}\right)+\sum_{\mathrm{j}} \sum_{\mathrm{t}} \gamma_{\mathrm{jt}}\left(\right.$ state $_{\mathrm{j}} \mathrm{x}$ time $\left._{\mathrm{t}}^{2}\right)+\pi \ln \mathrm{POP}_{\mathrm{ijt}}+\sum_{\mathrm{k}}$ $+\sum_{\mathrm{m}} \beta_{\mathrm{m}} \mathrm{X}_{\mathrm{mjt}}+\varepsilon_{\mathrm{ijt}}$

$\mathrm{i}=1, \ldots, \mathrm{N} \quad$ (demographic groups)

$\mathrm{j}=1, \ldots, \mathrm{M}$ (states)

$\mathrm{k}=19, \ldots, 39$ (age)

$\mathrm{t}=1990, \ldots, 1999$ (years)

where ln $\mathrm{N}_{-} \mathrm{OWB} \mathrm{B}_{\mathrm{ijt}}$ is the natural logarithm of the number of nonmarital births for women in demographic group i, state j, and year t. ${ }^{6}$ Equation (1) includes controls for state $\left(\delta_{\mathrm{j}}\right)$ fixed effects, state-specific (quadratic) time trends, and age $\left(\rho_{\mathrm{k}}\right)$ fixed effects. It also includes a state-year specific policy variable $\left(\right.$ policy $\left._{j t}\right)$ indicating a period of welfare reform in state $\mathrm{j}$, and time-varying state-level variables $\left(\mathrm{X}_{\mathrm{mjt}}\right)$ such as the current and one-year lag of the unemployment rate, the current and one-year lag of per-capita income, and the crime rate. The policy variables $\left(\right.$ policy $\left._{j t}\right)$ are measured with a nine-month lag so as to reflect the political climate at the time of conception. Finally, equation (1) includes the logarithm of population (ln POP), which is an estimate of the number of women in each demographic group in state $\mathrm{j}$ and year t. Although not shown, we also allow the effect of population to differ by age. We control for population instead of constructing fertility "rates" (births/population) because we have population

\footnotetext{
${ }^{5}$ Moffitt (1998) presents original analyses that illustrate the importance of examining the population most affected by welfare reform, namely low-income or less-educated women. We also use within-state variation in welfare policy, an approach advocated by Moffitt (1998).

${ }^{6}$ In order to obtain a closer match of policy environment to conception date, we divided years into two six month periods. So there are two observations per year for each demographic group representing the number of births in the first six months and second six months of the year. We assigned the policy variable in effect nine months prior to the first of the year for births in the first six months of the year and nine months prior to July 1 for births in the second six months of the year.
} 
estimates by year, state, age and race, but not by education and marital status within these groups. We explore the consequences of this limitation and discuss this issue in greater detail below. ${ }^{7}$ We use least squares regressions weighted by the population in each state, year and demographic group to estimate the models. We also adjust standard errors for clustering within state (Bertrand et al. 2002).

To characterize the policy environment, we focus on a few key aspects of state and federal welfare reform: time-limited benefits, exemptions from work requirements, and sanctions for noncompliance (Grogger et al. 2002). In some models, we also use a characterization of welfare policy that is common in the literature and include dummy variables for whether a state had implemented an AFDC waiver or TANF. We discuss the policy variables in greater detail below, but we note that because many of the policies were implemented during a relatively short interval, particularly TANF, we opted to control for time effects using state-specific (quadratic) trends instead of year dummy variables. The advantage of this specification is that it allows for separate state trends, which statistical tests revealed to be significant. The disadvantage is that it is somewhat restrictive in that it allows only for a quadratic trend. However, the relatively short period of time under investigation mitigates this problem. In addition, the DD analysis is intended to control for any unmeasured state-specific effects.

We estimate equation (1) using two samples: women in the target group and women in the comparison group. We also obtain DD estimates by comparing (i.e., taking the difference between) estimates of the parameter $\left(\alpha_{1}\right)$ for these two samples. We expect estimates associated with the treatment group to be more negative (less positive) than those associated with the control group because welfare reform should reduce fertility more in the treatment group than in the control group. We obtain DD estimates by pooling the data and allowing all coefficients to differ by whether or not a woman is in the target or comparison group. This is the least restrictive specification of the DD model and and specification tests rejected the more restrictive models.

\footnotetext{
${ }^{7}$ We also estimated all models using the number of births instead of the natural logarithm of the number of births. Results from this alternative specification are presented in the appendix for non-Hispanic, white women. The results do not differ qualitatively from those presented in the text.
} 
The difference-in-differences (DD) procedure is intended to isolate the effect of welfare reform from other determinants of out-of-wedlock birth that vary over time, across states, and over time within states. Most importantly, the DD approach potentially solves the difficult problem of controlling for unmeasured time-varying state effects (Moffitt 1998). It does so by employing a within-state control or comparison group. The logic is that of a classical experiment. The treatment, or target, group consists of women most likely affected by changes in welfare policy. The control, or comparison, group consists of women unlikely to be affected by changes in welfare policy. Under the assumption that members of the treatment and control groups are affected equally by unmeasured determinants of fertility that vary over time within a state, DD estimates can be interpreted as a causal effect of welfare reform. To support this interpretation, we include in equation (1) state-specific (quadratic) time trends, and several time-varying state-specific variables, which help to further control for time-varying, state-specific effects that may confound estimates of interest.

Three potential problems with the DD procedure merit comment. First, we have defined treatment and control groups on the basis of marital status. This is problematic if welfare reform affects marriage. If so, estimates of the effect of welfare reform on fertility will be a combination of a behavioral response — changes in fertility behavior — and a compositional effect — changes in the pool of married and unmarried women. Since both are effects of welfare reform, this problem is primarily a matter of interpretation. However, it is also possible to estimate the behavioral response in this context. Accordingly, we estimate some models for a pooled sample of married and unmarried women, and use only educational attainment to define treatment and control groups. In this case, the treatment group consists of women with a high school degree or less and the control group is women with more than a high school degree. Changes in the fertility of the less-educated group associated with welfare reform will reflect a purely behavioral response because population composition is unlikely to be affected by welfare reform. A disadvantage of this alternative approach is that fewer women in the treatment group are likely to be affected by changes in welfare policy, thereby muting the effect of welfare reform. 
The second potential problem is that the two groups only approximate true treatment and control groups. Ideally, the entire treatment group would be at risk of going on public assistance and the entire control group would not be at risk. Obviously, none of our treatment and control groups meet this standard. We investigate the likely extent of this "contamination" problem using data from the 1994 Current Population Survey. Table 1 presents mean public assistance receipt by education and marital status for women with children (i.e., mothers). The figures in the table clearly show that education and marital status are strongly correlated with public assistance receipt, and marital status has a particularly large effect, reflecting the eligibility criteria for welfare. For example, approximately 57 percent of lesseducated ( $<12$ years) unmarried mothers received public assistance in 1993 (i.e., the year prior to the interview) compared to only 11 percent of less-educated married mothers. These figures illustrate that less-educated, unmarried women are a particularly relevant group for the study of the effect of welfare reform. Education is also highly correlated with welfare receipt. In sum, while the figures in Table 1 demonstrate that using educational attainment and marriage to define treatment and control groups is reasonable, the classification error that results (i.e., the control group is, in fact, at some risk of welfare use) will lead to a downward bias in the DD estimates of the effect of welfare reform. The final potential problem with the DD procedure is whether the comparison groups are valid. The answer to this question depends on whether in the absence of welfare reform, unmeasured state-specific time variation in fertility is the same for the target and comparison groups. While there is no definitive answer to this question, one way to assess the adequacy of the comparison group is to carry out the DD procedure in a period where no policy change has taken place by constructing a pseudo policy that arbitrarily divides calendar time into a before- and after-period. If the comparison group is adequate, DD estimates should be zero in such circumstances. In our case, the period between 1990 and 1993 is one in which very little state welfare reform has taken place and there was as yet no federal reform.

Accordingly, we divide the period into two: 1990-1 and 1992-3, treating 1992-3 as the after period. We then obtain DD estimates for the three race/ethnic groups that are the focus of this paper. The results indicate that in all but one case, DD estimates are small and not statistically significant. The only DD 
estimate that was non-zero and statistically significant was for the sample of Hispanic women when unmarried women with between 13 to 15 years of education was used as a comparison group. Overall, these results provide support for the validity of our research design.

\section{Data}

The primary data for the analysis are individual birth records submitted by hospitals to state vital registration offices. All 50 states and the District of Columbia collect detailed information on individual births and report them to the National Center for Health Statistics (NCHS). We use the Detailed Natality Files made available by NCHS for the years 1990 to 1999. Information for each birth includes date and place of birth, and a variety of demographic characteristics of the mother such as age, race, parity, education and marital status. We limit the sample to women between the ages of 19 and $39 .{ }^{8}$ We omit teens from the analysis because there is little variation in educational attainment or marital status and, as a result, these characteristics do not effectively sort teenagers into target and comparison groups.

Although the NCHS Natality Files are relatively complete, some states do not collect all the necessary demographic data each year. Four states - California, North Dakota, Ohio, and Washingtondid not report educational attainment in some years between 1990 and 1992. However, by 1993, all states and the District of Columbia reported the education of the mother. Perhaps the most problematic variable is marital status, which affects counts of nonmarital births (Ventura and Bachrach 2000). In Michigan and Texas, reporting procedures resulted in severe undercounts of nonmarital births from 1990 to 1992. Reporting changes in California and New York City in 1995 and 1997, respectively, generated significant changes in the counts of nonmarital births. Similar, though less severe problems occurred in Nevada and Connecticut in the late 1990s. ${ }^{9}$ In light of these classification problems, we re-estimated some models in

\footnotetext{
${ }^{8}$ We also re-estimated all models presented below using a sample of women between the ages of 19 and 29. Results, contained in the appendix, were similar to those presented below.

${ }^{9}$ In California and New York, marital status of the mother is inferred from a paternity acknowledgment or missing father's name on the birth certificate. Prior to 1996, California, Connecticut, Nevada, and New York City depended on a comparison of the mother's and father's name. In 1997, California and Nevada changed from inference to a direct question and New York City changed to an inferential system comparable to upstate New York. Finally,
} 
which we used marital status to stratify the sample but omitting large states (CA, NY, MI, and TX) that changed data collection procedures. The results from these models were quite similar to those reported below. Therefore, we do not present these results, but they are available upon request.

The dependent variable in the analysis is the natural logarithm of the count of births in each category, defined by year, state, age, race, martial status, and education. Alternative estimates were obtained using the number of births and were qualitatively the same as those reported below, but we include some of these estimates in the appendix for review. The regression models include the logarithm of population as a control. This specification is quite similar to using the logarithm of the birth rate as the dependent variable, but the effect of the logarithm of population is not constrained to equal one. In either case, it is necessary to obtain estimates of the population of women in each demographic group, but no data source is truly adequate for this purpose. The Census Bureau provides population estimates by year, state, sex, single year of age, and race, but not by education and marital status. Obviously, there will be some measurement error as a result of using the Census data since the population controls do not correspond perfectly to exposure to the risk of the event measured by the dependent variable.

In order to examine whether or not this measurement error is important, we used the Current Population Survey to obtain population estimates for the more narrowly defined subpopulations, and reestimated the model using these population controls. We limit this analysis to large states for which population estimates derived from the CPS are most reliable. ${ }^{10}$ The results strongly indicated that measurement error resulting from the use of the Census population estimates has little effect on our estimates: estimates (not shown, but available from the authors) obtained using the more detailed CPS population estimates were very similar to those obtained using the coarser Census population estimates.

Connecticut added a direct question in mid-1998. A review by NCHS of Connecticut's birth data for 1998 indicated the proportion of births to unmarried women was somewhat higher under the inferential method than in the last six months when marital status was based on a direct question.

${ }^{10}$ Population estimates can be obtained using the weights provided by the CPS. For small states, population estimates contain a significant amount of error because of the small samples and the detailed demographic breakdowns we are using. 
The data on welfare policies is drawn from Assistant Secretary for Planning and Evaluation of the Department of Health and Human Services, as well as from the Urban Institute (www.urban.org/content/Research/NewFederalism/Data/StateDatabase/StateDatabase.htm) and the State Documentation Project of the Center on Budget and Policy Priorities (see www.cbpp.org and www.spdp.org/tanf.htm ) We focus on a few key aspects of state and federal welfare reform - timelimited benefits, exemptions from work requirements, and sanctions for non-compliance — and characterize the policies in three ways. In some models we consider solely whether or not a state had time-limited benefits (pre- or post-TANF time limit). Time-limited benefits represent the largest financial change produced by welfare reform, and studies have demonstrated that time limits have significant effects on welfare caseloads and employment (Grogger 2000, Grogger et al. 2002; Kaushal and Kaestner 2001). We also characterize welfare policy as a set of dummy variables to indicate the extent of reform. Many of the provisions of welfare reform that we examine were implemented simultaneously by states through waivers or in response to PRWORA, and have been characterized as policy packages (e.g., Myers, Gornick and Peck, 2001; Grogger et al. 2002). We place a state in the most extensive reform category if it has time-limited benefits, exempts from work requirements only women with children under six-months of age, and imposes financial sanctions for first time non-compliance and full sanctions for repeat non-compliance. A state is in the least extensive category if it has only time-limited benefits. The remaining category includes states with other combinations of these three policies. The reference group is states with none of these policies. Finally, we follow the earlier literature and estimate models that include dummy variables for whether a state had implemented an AFDC waiver or TANF.

\section{Results}

We begin by reviewing time trends in aggregate data. Rates of childbearing among unmarried women by race and ethnicity are displayed in Figure 1. There is no prominent break in any of the series following 1996, the year of passage of PRWORA. Rates of non-marital fertility fell steadily for black women, rose slightly among white women, and were essentially unchanged for Hispanic women over the 
1990s. Figures 2 through 4 present fertility rates for married and unmarried women with 12 or fewer years of education for non-Hispanic whites, non-Hispanic blacks, and Hispanics, respectively.

Unmarried women with little education are the populations most likely to be affected by welfare reform. Rates of non-marital fertility among less-educated white women generally increased over the 1990s, while rates of martial fertility declined in the first half of the 1990s and increased in the second half (Figure 2). Figure 3 tells a similar story for less-educated black women, except that rates of non-marital fertility actually increased slightly in the late 1990 s, after declining in the early part of the decade. The increase at the end of the 1990s could be the result of delayed fertility among less-educated black women, since rates of teen childbearing among black women have been on the decline since the early 1990s. Among Hispanic women we observe a rise in non-marital childbearing to about 1994, after which rates remain relatively flat (Figure 4).

Table 2 presents regression estimates of the effect of welfare reform on the fertility of nonHispanic, white women. Each of the first four columns of the table corresponds to a different sample. The first two columns show estimates for the two groups we consider to be most likely to be affected by changes in welfare policy, as these groups have relatively high rates of welfare use. Columns three and four show estimates for two comparison groups - samples of women unlikely to be significantly affected by changes in welfare policy. We expect the effects of welfare reform to be larger (i.e., more negative) in the first two columns than in columns three and four. The last four columns show the DD estimates; for each of the two target groups, we calculate two DD estimates by alternating the comparison group.

Within each column, we present estimates from three separate regression models that differ by the characterization of welfare policy. The top panel (row one) includes two dummy variables denoting AFDC waivers and TANF. The middle panel (row two) includes an indicator of whether or not a state had time-limited benefits, which may have been either pre- or post-TANF, as eight states implemented time limits as a part of an AFDC waiver prior to TANF. Finally, the bottom panel (row three) presents estimates from a model that characterizes welfare policy by the extent of reform from most extensive to least extensive with the reference category being no reform. Again, this characterization of welfare 
reform policies does not differentiate between policies implemented as part of an AFDC waiver or through TANF.

Estimates in the top panel of Table 2 indicate that, in general, AFDC waivers and TANF were associated with an increase in fertility for all four demographic groups. AFDC waivers had a relatively large effect indicating increases in fertility of approximately six percent. However, only one of the estimates is statistically significant, and in this case only marginally so $(0.10<\mathrm{p}<0.05)$. Difference-indifferences estimates are shown in the last four columns and all of the estimates are statistically insignificant and most are small in magnitude. The largest estimate suggests that TANF was associated with a three percent increase in fertility for unmarried women with less than 12 years of education. Row two presents the estimates of the effect of time-limited benefits. These estimates indicate that timelimited benefits were not significantly associated with the fertility of non-Hispanic, white women. All of the estimates are small and statistically insignificant. DD estimates are also statistically insignificant and small - the largest effect indicates a decrease in fertility of 1.2 percent.

The next estimates discussed are from models that characterize welfare reform in more detail, and these are listed in the bottom panel of the table. Specifically, in this model, we group states according to whether or not they had one or more of the following: time-limited benefits, exemptions from work requirements for women with very young children, and financial sanctions for non-compliance. Again, we expect fertility to decline more in states with more extensive reforms. Estimates in panel three confirm our earlier findings, and generally indicate that welfare reform is not associated with fertility of unmarried and low-educated women. Only one of the estimates in columns one through four is statistically significant (marginally) and all the estimates are relatively small—suggesting effects of less than six percent. Virtually all of the DD estimates are also statistically insignificant and small in magnitude. Overall, estimates in Table 2 suggest that welfare reform had little effect on the fertility of non-Hispanic, white women.

As noted, defining treatment and control groups on the basis of marital status is potentially problematic. Welfare reform may have affected marital status, in which case the estimates in Table 2 
would confound the behavioral response and a selection effect. Importantly, both effects are due to welfare reform and thus, estimates in Table 2 are of interest even if marital status is endogenous. One way to sort out the two effects is to drop marital status from the definition of target and control groups. As Table 1 reveals, there is significant variation in welfare use among women defined on the basis of education alone; among mothers with less than a high school degree, 33 percent report receiving welfare benefits in the prior year where as only eight percent of mothers with between 13 and 15 years of education report such income. Therefore, we use less educated women as the target group and more educated women as the comparison group. Table 5 presents estimates from the analysis that uses these groups.

Estimates in Table 5 pertaining to non-Hispanic, white women are quite consistent with those in Table 2. Most of the estimates of welfare reform policy are small $(<$ six percent) and statistically insignificant. AFDC waivers and TANF are generally positively related to fertility while the other measures of welfare reform are more mixed. In this case, however, DD estimates are consistently positive and most are statistically significant, although all are small, suggesting increases in fertility of less than three percent. In sum, the estimates in Table 5 do not suggest that those in Table 2 are significantly affected by selection effects resulting from welfare reform's effect on marital status. Instead they confirm the results of Table 2 and suggest that state and federal welfare reform had little effect, or a small positive effect on fertility.

Table 3 presents estimates of the effect of welfare reform on the fertility of non-Hispanic, black women, and has the same format as Table 2. Estimates in columns one through four of the top panel indicate that AFDC waivers are negatively associated with fertility and TANF positively associated with fertility. Most of the TANF estimates are statistically significant and indicate that fertility increased between three to seven percent post TANF for the demographic groups shown in columns one through four; larger effects were found for members of the target group. DD estimates of the effect of AFDC waivers are mixed and only one is marginally significant. This suggests that AFDC waivers were not associated with fertility for non-Hispanic, black women. In contrast, DD estimates of the effect of TANF 
indicate a positive association between TANF and fertility and half the estimates are statistically significant and all are of the same approximate magnitude; estimates indicate that TANF was associated with a three to four percent increase in fertility of low-educated, unmarried black women.

Estimates of the effect of time-limited benefits, presented in row two, also indicate that this aspect of welfare reform was positively related to fertility. Estimates in columns one and two are statistically significant and indicate that time-limited benefits are associated with a four percent increase in fertility. Similar effects of time-limited benefits are found for less-educated married women (column four). However, time-limited benefits are not associated with the fertility of unmarried women with between 13 and 15 years of education. DD estimates of the effect of time-limited benefits are mixed and differ according to the comparison group used to construct them. They suggest that time-limited benefits were associated with a zero to four percent increase in fertility.

Finally, estimates in the bottom panel of Table 3 indicate that welfare reform as characterized was positively associated with the fertility of less-educated, unmarried women (columns one and two). About two thirds of the estimates in columns one and two are statistically significant and suggest an increase in fertility of two to six percent. However, there is little evidence of a dose-response effect. Estimates in columns three and four are more mixed in sign and none are statistically significant. DD estimates are also mixed in sign and most are not statistically significant. So, as was the case for non-Hispanic, white women, welfare reform does not appear to be associated with reductions in the relative fertility of lesseducated, unmarried non-Hispanic black women. If anything, TANF was associated with a small increase in fertility of two to four percent.

We also obtained estimates of the effect of welfare reform on the fertility of non-Hispanic, black women using target and comparison groups defined by education alone. These estimates are shown in Table 5. They confirm the findings just reviewed. TANF and policies highly correlated with it such as time-limited benefits were positively associated with fertility. DD estimates in Table 5 suggest an effect of four percent. Estimates in Table 5 also support the argument that welfare induced selection into marriage did not have a significant effect on estimates in Table 2. 
The third population we studied was Hispanic women, who can be of any race. Estimates of the effect of welfare reform on the fertility of this group of women are presented in Table 4. As noted, the reporting of marital status has been inconsistent in some states. We expected Hispanics to be particularly affected by problems with marital status reporting because of the large concentrations of Hispanics in states with reporting inconsistencies such as California, Texas and New York. Moreover, the way that California and New York altered reporting procedures is most likely to have affected Hispanics (Ventura and Bachrach 2000). In light of this concern, we re-estimated all models excluding states with known reporting problems: California and New York in all years, and Michigan and Texas prior to 1993. The estimates from these models were very similar to those reported in Table 4. Therefore, we do not report them, but they are available from authors.

Estimates in the top panel of Table 4 indicate a relatively large negative association between AFDC waivers and the fertility of low-educated, unmarried women (columns one and two). Estimates indicate that AFDC waivers were associated with a statistically significant, eight to nine percent decrease in the fertility of these two groups. A similar effect is found for unmarried women with between 13 and 15 years of education. In contrast, AFDC waivers are associated with an increase in the fertility of loweducated married Hispanic women. Consistent with this pattern, DD estimates suggest very different effects depending on which comparison group is used. If the estimates in column three are used, the DD estimates are small, positive and not statistically significant. If the estimates in column four are used, the DD estimates are large, negative and statistically significant. Our earlier analysis of the adequacy of the comparison groups suggests that married women with less than 12 years of education are the preferred comparison group. On this basis, we are led to prefer the DD estimates constructed using this comparison group, although we recognize that there is no definitive justification for this decision. ${ }^{11}$ Thus, our preferred estimates indicate that AFDC waivers had a negative and statistically association with fertility of Hispanic women. One possible explanation for this finding is the geographic concentration of 
Hispanics, which suggests that only a few states that had AFDC waivers and large Hispanic concentrations may be driving this result—notably California. Therefore, we re-estimated the model dropping California. In this case, the DD estimates of the effect of AFDC remained negative and significant although a bit smaller in magnitude — approximately seven percent. Finally, estimates of the effect of AFDC waivers in Table 5 are inconsistent with those in Table 4. When only education status is used to define target and comparison groups, estimates of the effect of AFDC waivers are small and not statistically significant.

Estimates of the effect of TANF are positive and statistically significant in the first three columns and negative and insignificant in column four. Given our preferences, we focus on the DD estimates constructed using the column 3 estimates. In these cases, DD estimates indicate that TANF had a negative and statistically insignificant association with fertility. The opposite characterization applies to the other DD estimates.

The middle panel of Table 4 shows estimates of the effect of time-limited benefits. Most estimates are positive and most are not statistically significant. DD estimates associated with time-limited benefits are also not significant. Finally, the bottom panel lists the estimates of the effect of welfare reform characterized as most to least extensive. Estimates in columns one through four are quite mixed and most are statistically insignificant. Similarly, DD estimates are mostly insignificant and have mixed signs. In sum, estimates of the effect of time-limited benefits and other aspects of reform, as characterized in the bottom panel, suggest that welfare reform was not statistically associated with the fertility of non-Hispanic women. Further supporting this conclusion are estimates in Table 5, obtained using the alternative definition of target and comparison groups.

\footnotetext{
${ }^{11}$ For example, Figure 4 is inconsistent with the findings from the DD analysis for 1991 to 1993 that was used to assess the adequacy of the comparison groups since the trend for the unmarried women with 13 to 15 years of
} 


\section{Conclusions}

Non-marital births are considered among the most important avenues to welfare dependence. Indeed, eligibility for federal cash assistance is limited to families with children, and eligibility for families headed by a married couple has been quite restricted. Consequently, the welfare caseload consists predominantly of unmarried women and their children, and unmarried women have high rates of welfare receipt. This fact, along with the relatively poor outcomes of children from single-parent families, motivated the authors of the 1996 welfare reform law (PRWORA). Changes in welfare policy that made cash assistance temporary and participation in the program more onerous were, in part, intended to discourage couples from having non-marital births. We have investigated whether PRWORA and earlier state welfare "waiver" reform efforts from which PRWORA drew many of its provisions, were associated with a reduction in nonmarital fertility in the 1990s. The evidence we presented suggests that welfare reform had relatively little effect on the fertility of less-educated, unmarried women. If anything, AFDC waivers were associated with a negative effect of seven to 10 percent on Hispanic women's fertility, and federal welfare reform was associated with a small positive effect of two to three percent for white and black women. However, the absence of a consistent set of findings--for example a similar effect of a given policy for women of all race/ethnic groups, and the predominance of insignificant effects-- leads us to conclude that, in general, state and federal reform have not affected fertility.

The absence of a finding of a significant effect of welfare reform on non-marital fertility is consistent with earlier literature that has found little relationship between AFDC benefit levels and fertility (Moffitt 1992). However, more recent studies have found consistent evidence of effects, although modest in size (Kearney 2001, Levine 2002). In comparison, our lack of a finding is surprising. Previous analyses have primarily relied upon variation in benefit levels across states and across time to identify effects of welfare on fertility. PRWORA and, sometimes, earlier state reforms represent the elimination of the entitlement to a benefit, a far more dramatic change in financial incentives than marginal or even moderate shifts in the benefit levels.

education appears to be similar to that of low-educated unmarried women. 
It is certainly possible that there has been an effect of welfare reform on non-marital fertility that we were unable to detect. For example, there may be strong cohort patterns in non-marital fertility; thus, exposure during the early teen years to a policy regime without a welfare entitlement might produce large behavioral changes for such "entering" cohorts but little change among older cohorts (e.g., Rindfuss 1991). In this case, a study that focuses on the cohort of younger women who entered their childbearing years after the imposition of welfare reform might uncover more evidence of an effect. We attempted to address this issue here by limiting the sample to women between the ages of 19 and 29 and re-estimating all models, but there was no evidence of an effect of welfare reform on the fertility of this group (results in Appendix Table 2). Kaestner, Korenman and O’Neill (2003) also examined the effect of welfare reform on teens and found some evidence that welfare reform has decreased disadvantaged teen's nonmarital fertility.

Another possible explanation for our findings is that more time may be needed for couples or women to adjust fertility behavior to policy changes. The argument against this hypothesis is the evidence that welfare reform has already had a substantial effect on work effort and welfare receipt (Kaushal and Kaestner 2001; CEA 1999; Schoeni and Blank 2000; Grogger 2000). Nonetheless, work and welfare use should be expected to respond more quickly since the actual provisions of the law (although not the rhetoric) were more clearly targeted to changing work effort and welfare dependency than to promoting marriage or reducing nonmarital fertility. 


\section{References}

Becker, G.S. 1981. A Treatise on the Family. Cambridge, MA: Harvard University Press.

Becker G. S. and H. G. Lewis. 1973. "On the Interaction Between Quantity and Quality of Children." Journal of Political Economy 81(2):S279-S288.

Bertrand, Marrianne, Esther Duflo and Sendhil Mullainathan. 2002. How much should we trust difference-in-differences estimates? NBER Working Paper 8841. March.

Camasso M. C. Harvey, M. Killingsworth, and R. Jagannathan. 1999. "New Jersey's Family Cap and Family Size Decisions: Some Findings From a Five-Year Evaluation.” Unpublished manuscript, Rutgers University.

Grogger, Jeff. 2000. Time limits and welfare use. NBER Working Paper 7709. May.

Grogger, Jeff, Lynn Karoly, and Jacob Klerman. 2002. Consequences of welfare reform: A research synthesis. DRU-2676-DHHS.

Horvath, Ann and Elizabeth Peters. 1999. Welfare waivers and nonmarital childbearing. Unpublished manuscript, Cornell University.

Kaestner, Robert, Sanders Korenman, and June O’Neill. (2003, forthcoming). The effect of welfare reform on

welfare use, fertility, and marriage of disadvantaged girls. Journal of Policy Analysis and Management.

Kaushal, Neeraj and Robert Kaestner. 2001. "Welfare to Work: Has Welfare Reform Worked?" Journal of Policy Analysis and Management 20(4), 699-719.

Kearney, Melissa Schettini. 2001. "Is there an effect of incremental welfare benefits on fertility behavior? A look at the family cap. Unpublished manuscript, Department of Economics, Massachusetts Institute of Technology.

Levine, P. B. 1999. “The Sexual Activity and Birth Control Use of American Teenagers.” Paper prepared for the NBER conference on An Economic Analysis of Risky Behavior Among Youth, November 5, 1999

Levine, Phillip. 2002. "The impact of social policy and economic activity throughout the fertility tree. Unpublished manuscript, Department of Economics, Wellesley College.

McLanahan, Sara and Gary S. Sandefur. 1994. Growing up with a single mother: What hurts, what helps. Cambridge: Harvard University Press.

Meyer, Bruce D. and Dan T. Rosenbaum. 2000. Making single mothers work: Recent tax and welfare policy and its effects. NBER WP 7491. January.

Meyer, Bruce and Dan T. Rosenbaum. 1999. Welfare, the Earned Income Tax Credit, and the labor supply of single mothers. NBER Working Paper 7363, September. 
Meyers, M. J.C. Gornick and L. Peck. 2001. Packaging support for low-income families: Policy variationacross the United States. Journal of Policy Analysis and Management 20(3): 456-483.

Michael, Robert T. and Robert J. Willis. 1975. Contraception and Fertility. In N.E. Terleckyj, ed. Household Production and Consumption. NY: NBER.

Moffitt, Robert A. 1992. The incentive effects of the US welfare system. Journal of Economic Literature 30(1): 1-61.

Moffitt, Robert A. 1999. The effect of pre-PRWORA waivers on AFDC caseloads and female earnings,income, and labor force behavior. In Sheldon H. Danziger, ed. Economic conditions and welfare reform. Kalmazoo, MI: Upjohn Institute.

Moffitt, Robert A. and Michele Ver Ploeg, Eds. 1999. Evaluating welfare reform: A framework and review of current work. Washington, D.C.: National Academy Press.

Moffitt, R. A. 1998. "The Effect of Welfare on Marriage and Fertility.” In Robert Moffitt, editor, Welfare, The Family, and Reproductive Behavior: Research Perspectives.Washington, DC : National Academy Press

Montgomery, M. and J. Trussell. 1986. "Models of Marital Status and Childbearing.” In O.

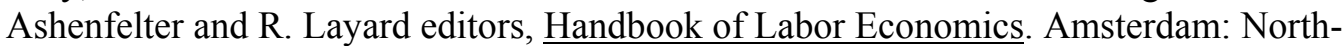
Holland Press.

O'Neill, David and June E. O'Neill. 1997. Lessons for welfare reform: An analysis of the AFDC Caseload and past welfare-to-work programs. Kalamazoo, MI.: W.E. Upjohn Institute for Employment Research.

O'Neill, June E. and M. Anne Hill. 2001. Gaining ground? Measuring the impact of welfare reform on welfare and work. Civic Report No. 17. Manhattan Institute.

Rindfuss, Ronald R. 1991. The young adult years: Diversity, structural change, and fertility. Population Association of America Presidential Address. Demography 28(4): 493-512.

Schoeni, Robert F. and Rebecca M. Blank. 2000. What has welfare reform accomplished: Impacts on welfare participation, employment, income, poverty and family structure. NBER Working Paper 7627, March.

US DHHS. 2000. Admistration for Children and Families, http://www.acf.dhhs.gov/news/tables.htm, June 6, 2000. Accessed June 16, 2000.

Ventura, Stephanie J. and Christine A. Barchrach. 2000. Nonmarital Childbearing in the United States 1940-99. National Vital Statistics Reports 48(16). Hyattsville, MD: NCHS. 


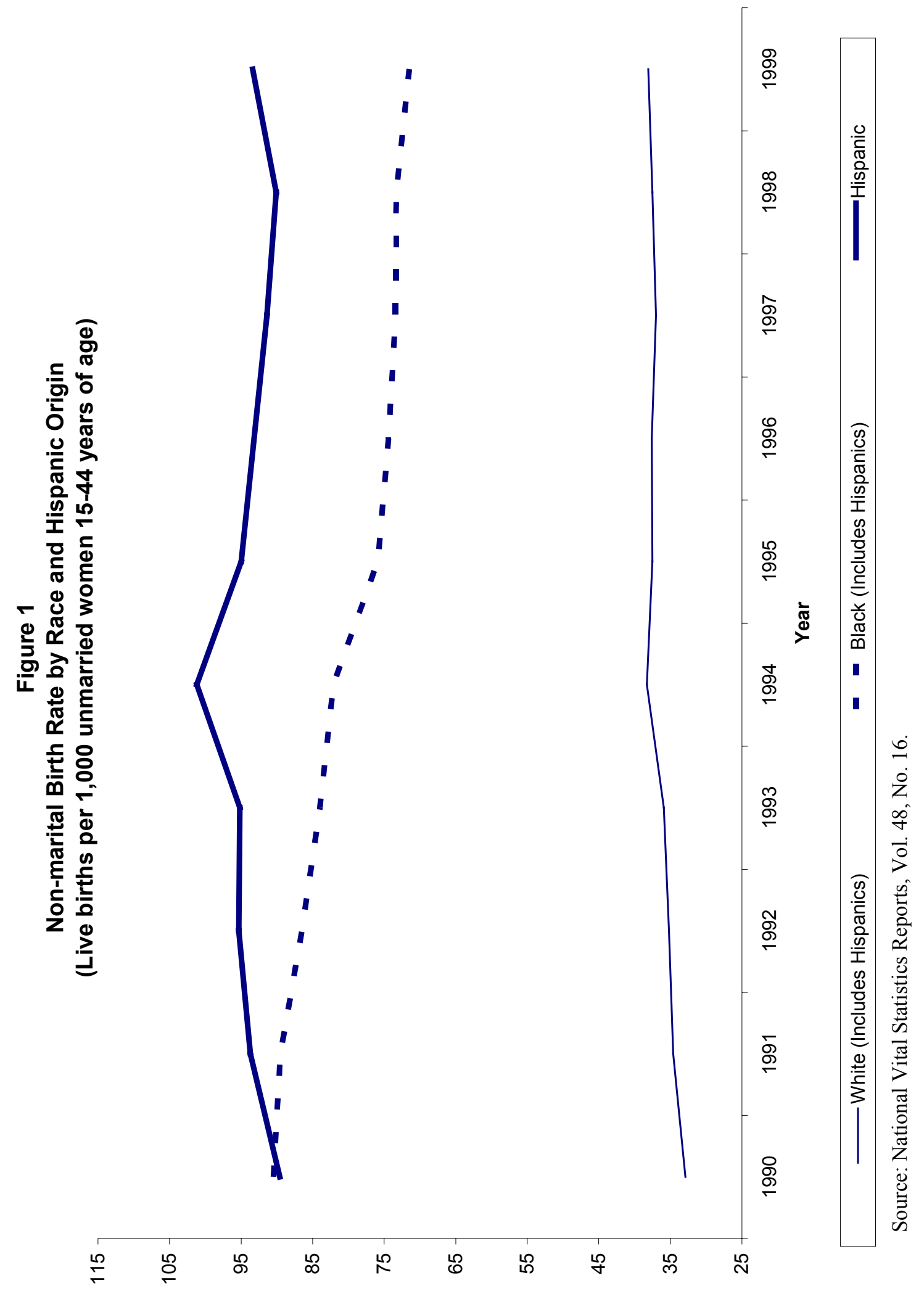




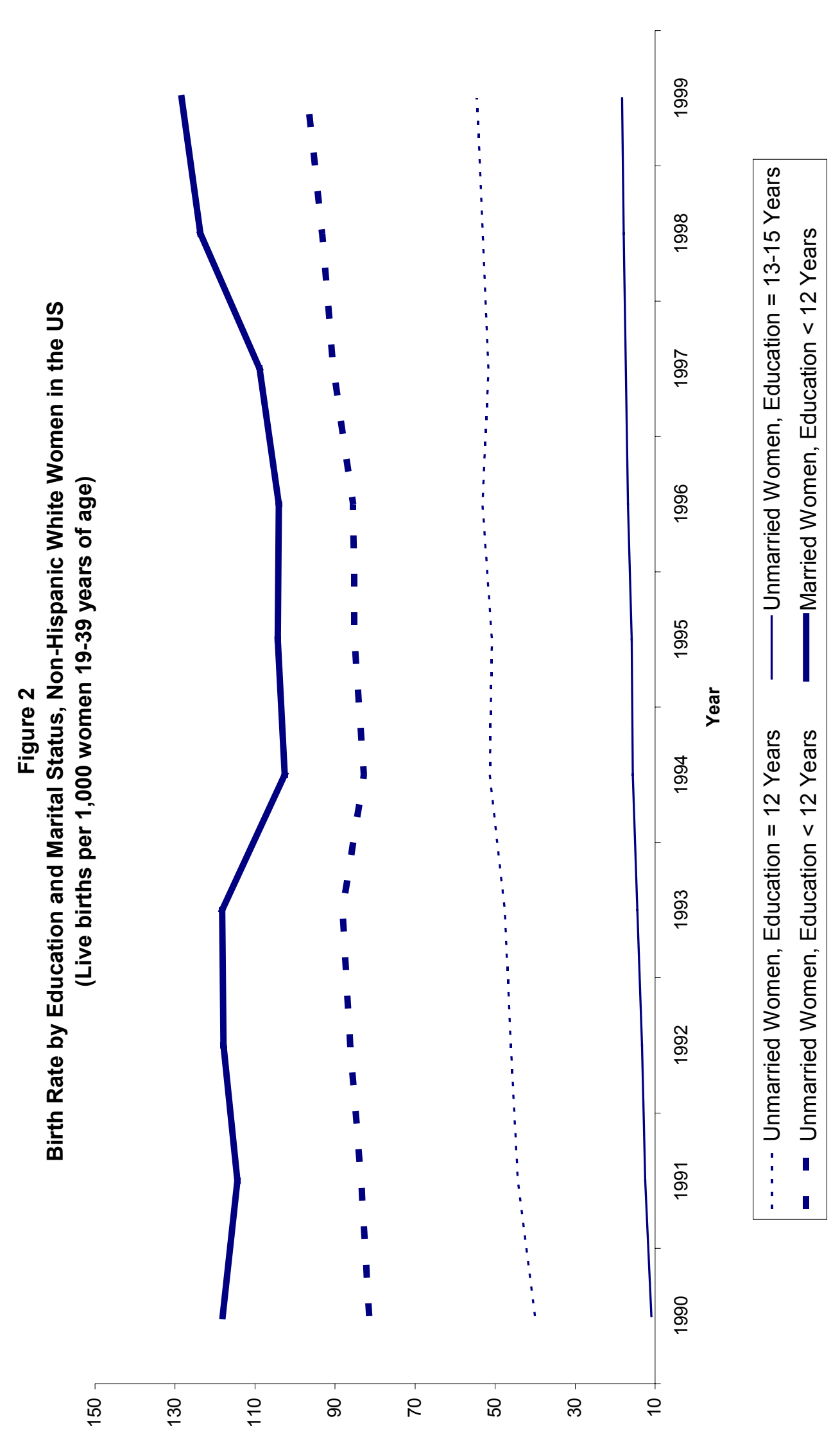




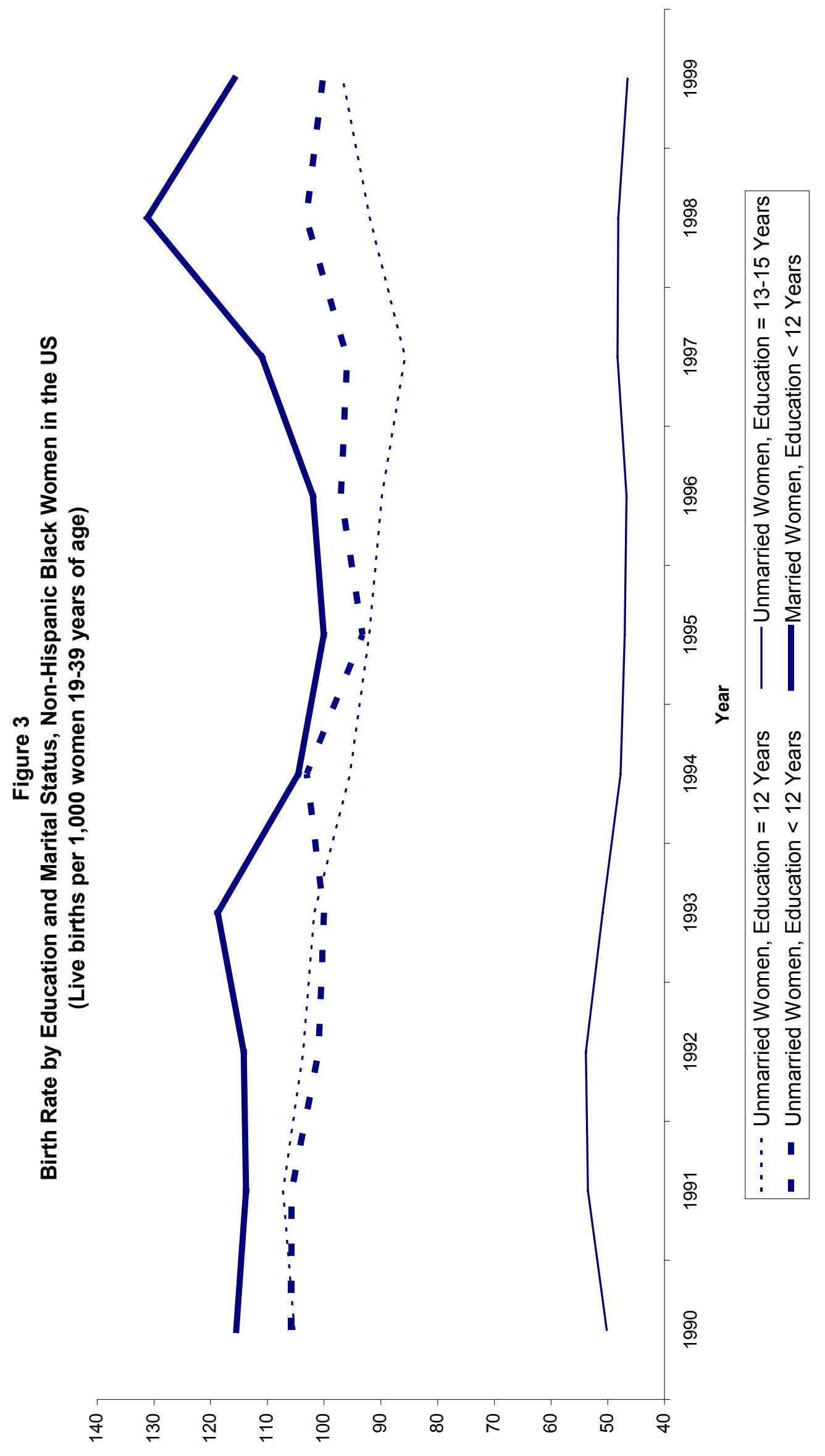




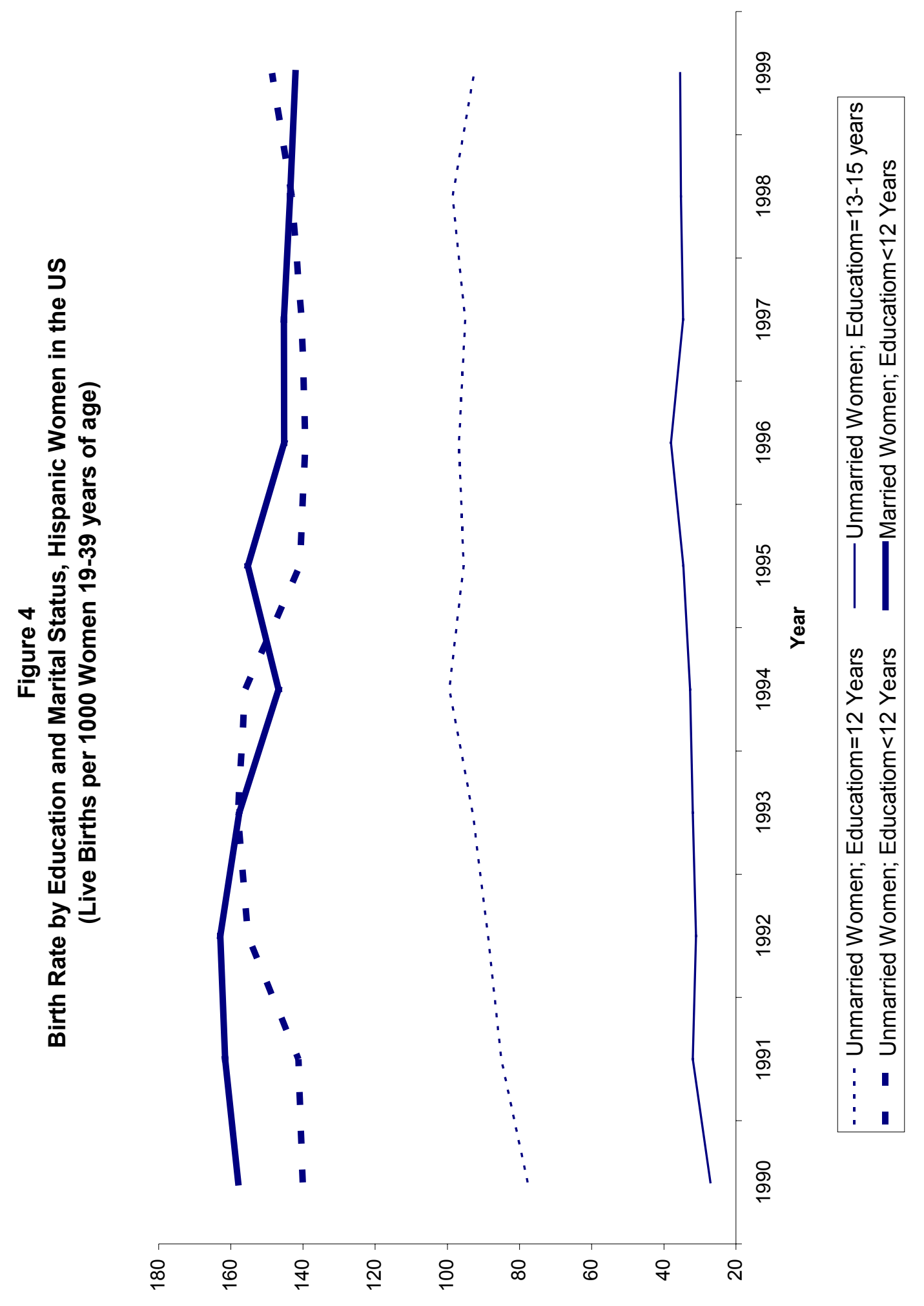


Table 1

Proportion of Mothers Receiving Public Assistance By Education and Marital Status, 1994

\begin{tabular}{|l|c|}
\hline Demographic Group & $\begin{array}{c}\text { Received Public } \\
\text { Assistance in Past Year }\end{array}$ \\
\hline Less than High School & 32.6 \\
High School Degree & 15.6 \\
More than High School (13 to 15 years of education) & 7.6 \\
\hline Less than High School Degree - Married & 11.3 \\
Less than High School Degree - Not Married & 56.7 \\
\hline High School Degree - Married & 4.5 \\
High School Degree - Not Married & 36.3 \\
\hline More than High School (13 to 15 years of education) - Married & 1.9 \\
More than High School (13 to 15 years of education) - Not Married & 18.5 \\
\hline
\end{tabular}

Source: 1994 Current Population Survey; sample includes only women with children. 


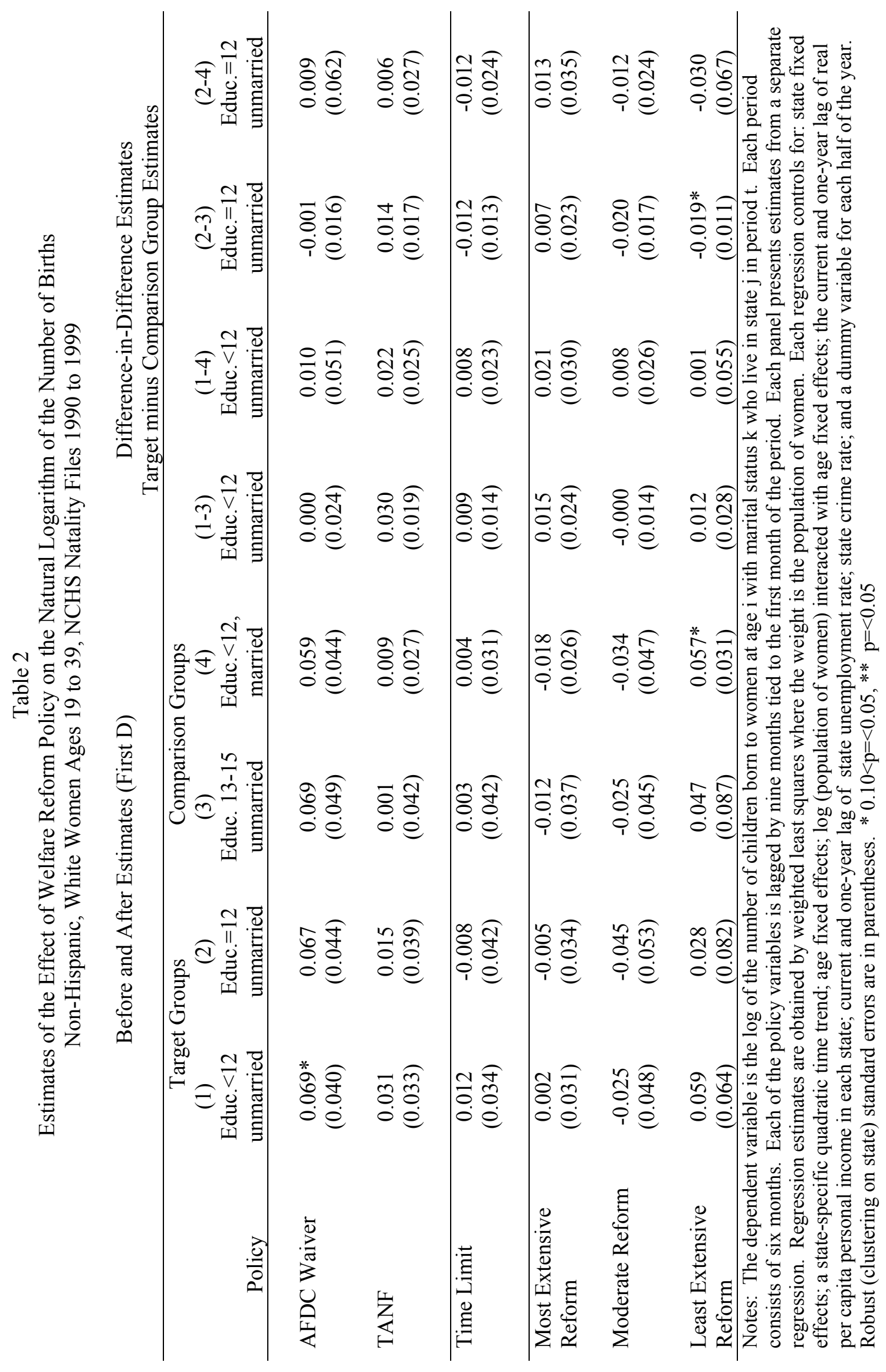




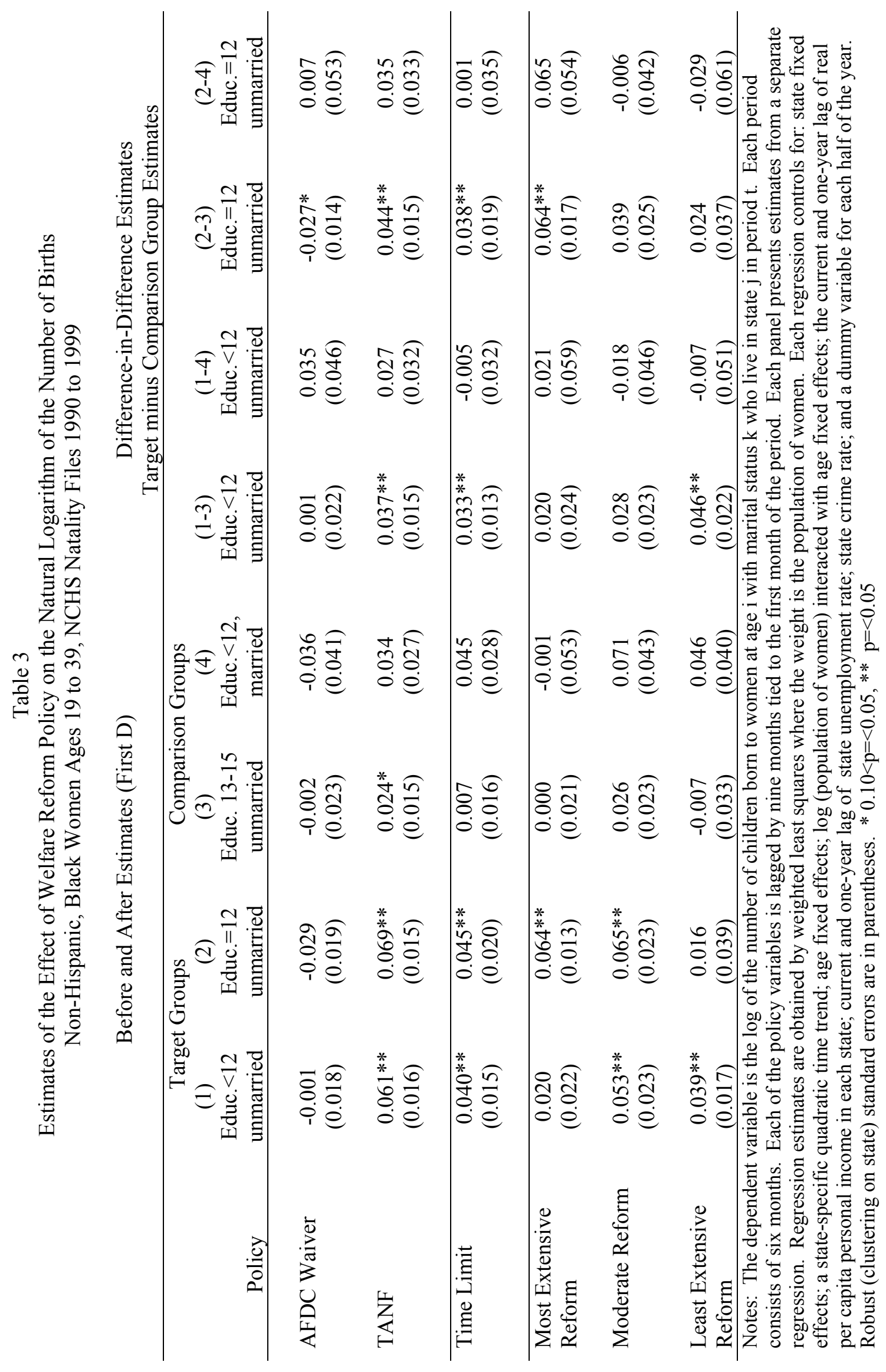




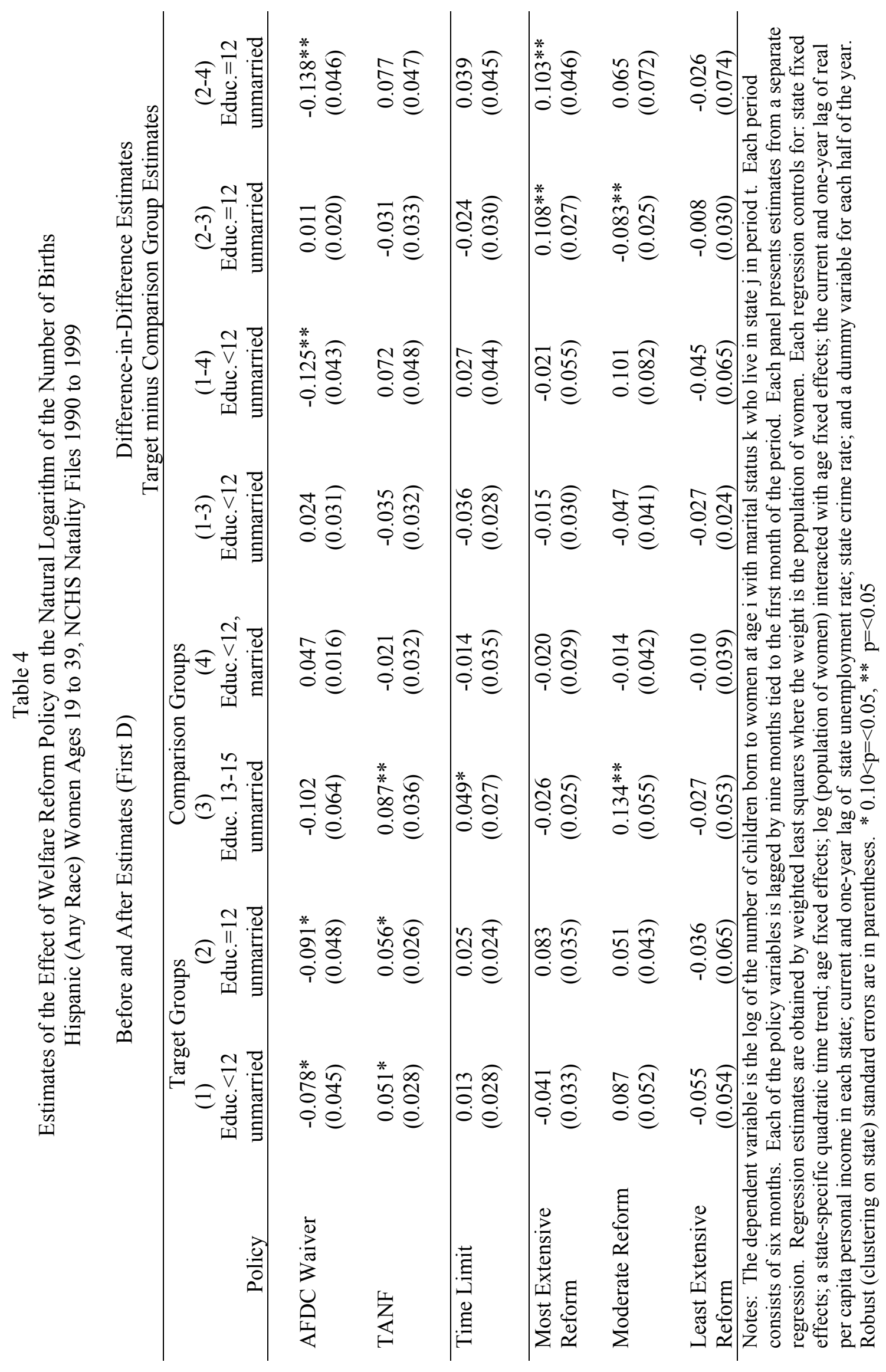




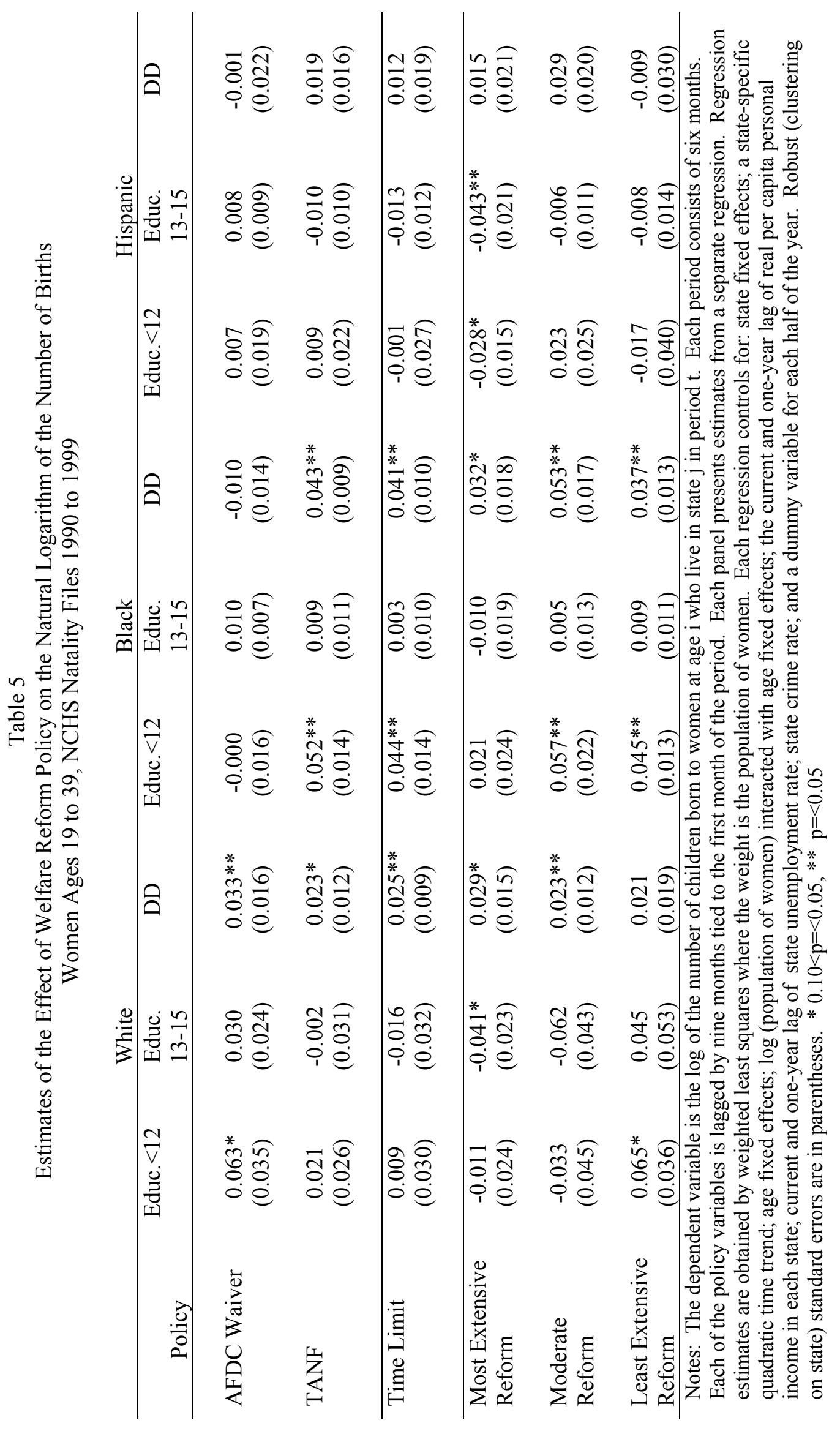




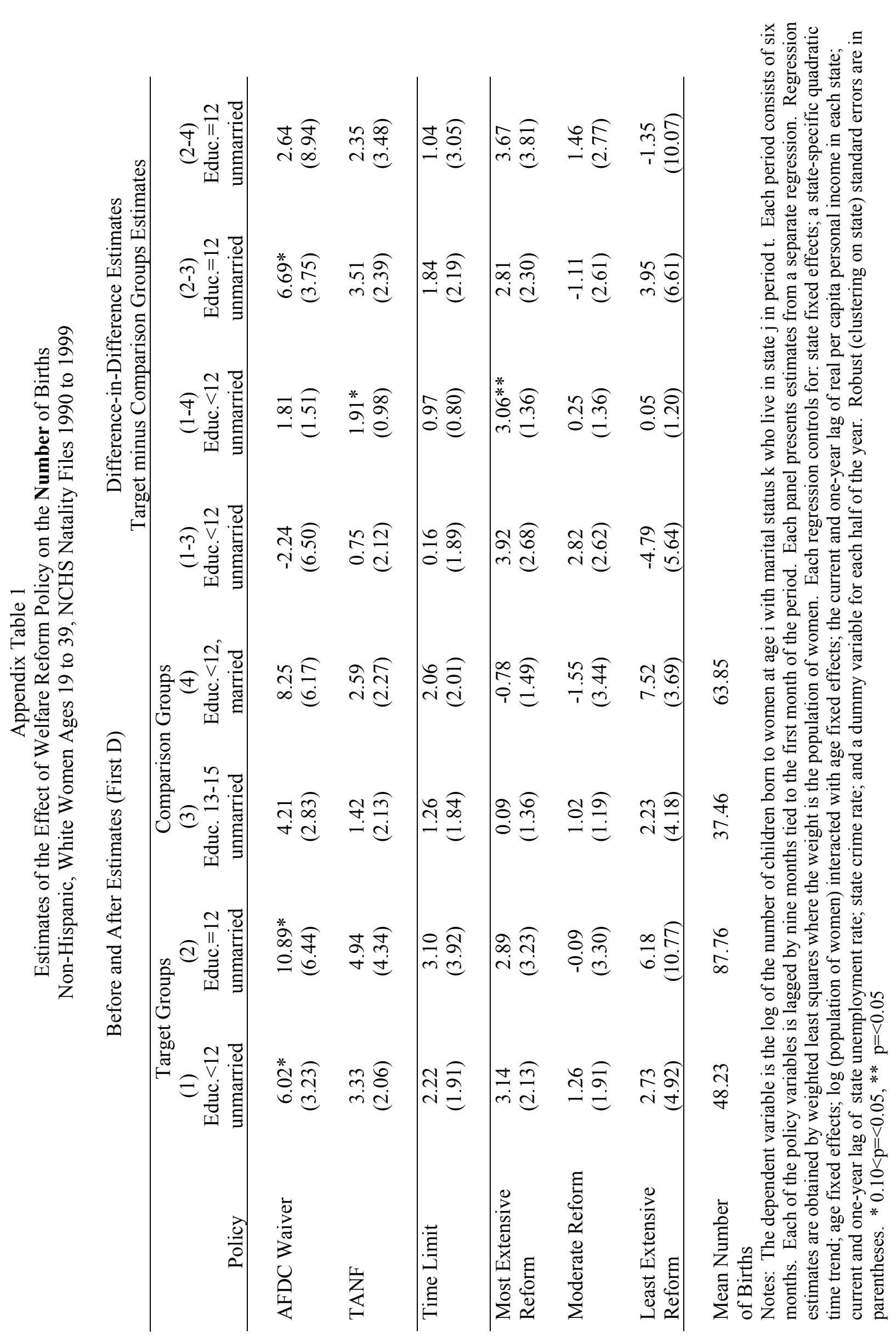




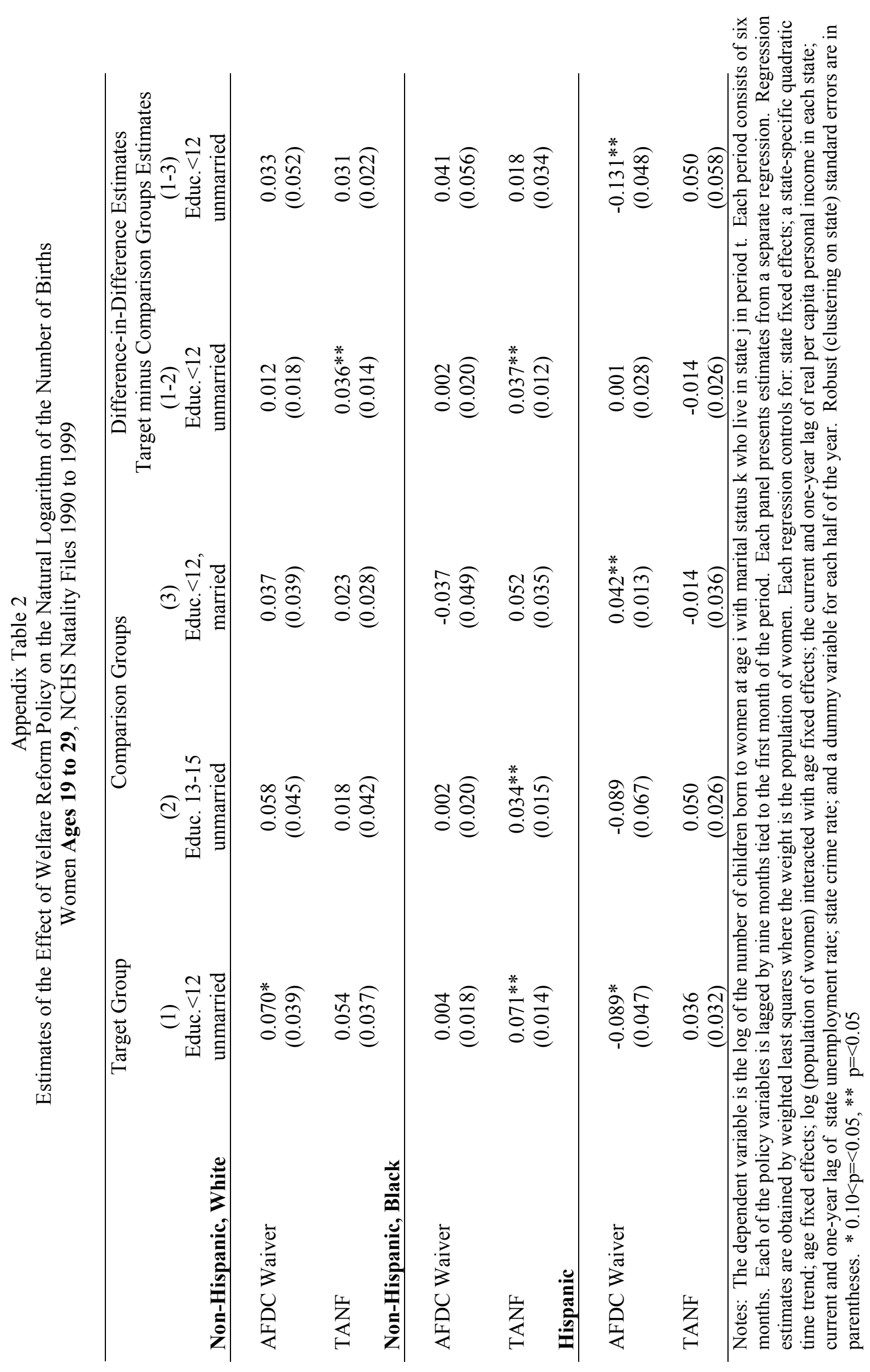

